Case Report

\title{
Spinal Cord Stimulation for the Treatment of Chronic Renal Pain Secondary to Uretero-Pelvic Junction Obstruction
}

\author{
Chong H. Kim, MD and Mohammad Issa, MD
}

From: West Virginia University,
Morgantown, WV.

Dr. Kim is Assistant Professor with

the Department of Neurosurgery, West Virginia University, Morgantown, WV. Dr. Issa is a Resident Physician with the Department of Behavioral Medicine and Psychiatry, West Virginia University, Morgantown, WV.

Address correspondence: Chong H. Kim, MD

West Virginia University Morgantown, WV

E-mail:wp34@hotmail.com

Disclaimer: There was no external funding in the preparation of this manuscript.

Conflict of interest: None.

Manuscript received: 09/09/2010

Revised manuscript received: $12 / 05 / 2010$

Accepted for publication: 01/03/2011

Free full manuscript: www.painphysicianjournal.com
Background: Chronic renal pain secondary to uretero-pelvic junction obstruction (UPJO) is common but remains poorly understood. Patients with UPJO experience frequent infections, renal calculi and pain. Management options for patients with this condition are traditionally limited to surgical interventions to eliminate the obstruction.

Spinal Cord Stimulation (SCS) has gained widespread popularity for the treatment of numerous conditions from complex regional pain syndrome to failed back syndrome. With continued success, the possible use of SCS has steadily increased.

Although a significant number of patients with severe chronic renal pain will transiently respond to analgesics and physical interventions such as autonomic sympathetic blocks, substantial long-term pain relief is usually lacking. SCS therefore might be a welcome addition to the treatment of moderate to severe chronic renal pain. .

Objective: This article presents a case of using spinal cord stimulation in the management of chronic renal pain secondary to Uretero-pelvic junction obstruction.

Design: Case report

Setting: Academic University Pain Management Center

Methods: A 38-year old female presented with a 15-year history of persistent right sided flank pain secondary to congenital uretero-pelvic junction obstruction. After failing to respond adequately to stenting, medications and nerve blocks, a trial of spinal cord stimulation and subsequent permanent implantation of a spinal cord stimulator (SCS) were performed.

Results: The patient reported significant improvement in pain, overall functioning and no consumption of opioids during the SCS trial and following system implant.

Limitations: A case report.

Conclusion: Spinal cord stimulation might be an option in the management of chronic renal pain secondary to Uretero-pelvic junction obstruction.

Key words: spinal cord stimulation, renal pain, uretero-pelvic jnction obstruction, visceral pain, flank pain, pelvic pain

Pain Physician 2011; 14:55-59

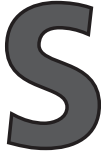

pinal Cord Stimulation (SCS) has gained widespread popularity for the treatment of neuropathic pain of various etiologies (1-9). A few recent case reports suggested the success of SCS in suppressing severe, long-standing abdominal and pelvic visceral pain (10-16)

Although a significant number of patients with severe chronic renal pain will transiently respond to analgesics and physical interventions such as autonomic sympathetic blocks, substantial long-term pain relief 
is usually lacking. SCS could therefore be a welcome addition to the treatment of moderate to severe chronic renal pain (17-28).

\section{Case Report}

A 38-year-old female with a 15 year history of right sided flank pain was referred by the Urological Service for evaluation. She had initially presented with frequent urinary tract infections as a teenager with associated pain. The patient was treated with antibiotics and as needed, pain medications. With increased frequency of infections and severity and duration of pain, she was referred to the Urologic Service for further evaluation. After extensive testing and imaging, the patient was diagnosed with congenital ureteropelvic junction obstruction (UPJO). Despite different interventions, including stenting, the patient continued to experience severe pain. With the increased severity and constant nature, she was tried on a long acting opioid regimen by her primary care physician after obtaining limited benefit with as needed short acting opioid regimen. With the exhaustion of all other treatment options and limited benefit from escalation of opioid pain medications, the patient was considering elective nephrectomy as her final treatment option. As a result, prior to proceeding with a robotic nephrectomy, the patient was referred for evaluation.

The patient described a constant baseline pain and deep ache that was primarily located in her right flank and lower abdominal area. She also noted episodes of intense, severe, cramping, sharp, stabbing, and burning pain that radiated to her right lower abdomen and pelvis, occasionally to her back. The patient denied any association with movement or position change. She had tried physical therapy (PT), various modalities, behavioral health services, over-the-counter (OTC) pain medications, muscle relaxants, various neuromodulators and opioid medications with only relative benefit, mostly from opioid medications. However, she noted sedation and lethargy with opioid medications, severe enough to impact her routine activities and overall daily function. As a result, she had been managed with 4-6 tablets of hydrocodone/acetaminophen 10/325 daily with only minimal satisfaction.

On examination, the patient was a pleasant female, appearing her stated age. She reported a baseline pain level of $8 / 10$ on the visual analog scale (VAS) with $10 / 10$ on episodes of flare-up that now routinely occurred multiple times daily. She had some pain on deep palpation of her abdomen and right flank region with an otherwise unremarkable exam.
Based on the location of the pain and symptoms, the patient was informed of the limited options that were available for treatment. She was offered sympathetic plexus blocks for her associated lower abdominal and pelvic pain as well as spinal cord stimulation (SCS). The patient underwent a celiac plexus block without benefit. However, the patient obtained benefit, but with limited duration, of her pain after a right superior hypogastric block.

After review of the information on SCS and discussion with the Urological Service, the patient elected to proceed with the SCS trial prior to surgical intervention for removal of her kidney. The patient was evaluated and cleared by the Behavioral Health and Psychiatric Services.

The patient underwent a 7 day SCS trial. A single octad lead (Boston Scientific, Valencia, CA) was entered at the L1-2 level and advanced to the mid T7 vertebral body, slightly right on center (Fig. 1). The stimulation parameters were amplitude of $7.0 \mathrm{~mA}$, a pulse width of $160 \mathrm{~ms}$ and a frequency of $60 \mathrm{~Hz}$. During the trial period, she noted greater than $85 \%$ relief of her pain. During the week, the patient stated that she did not require any oral pain medication. She also noted overall satisfaction with increased function, improved sleep and overall improvement of her mood. After documentation of the successful trial, she underwent a percutaneous permanent lead implantation 4 weeks later. On subsequent follow up visits, the patient reported complete satisfaction in pain relief and coverage. Nine months after her implantation, she continued to not require any regular opioid pain medications and was managed on OTC anti-inflammatories, used on an as needed basis.

\section{Discussion}

Described here is a case of severe chronic lower abdominal and pelvic pain secondary to UPJO, which almost completely resolved with SCS. The patient reported a significant improvement in pain, overall functioning, and no consumption of opioids during the SCS trial and following system implant.

UPJO is one of the most common congenital abnormalities of the urinary tract, with an annual incidence of 5 per 100,000 (29). UPJO can be classified as congenital or acquired in origin. Congenital UPJO is typically characterized by an intrinsic luminal narrowing caused by an aperistaltic ureteric segment secondary to muscular discontinuity. However, other etiologies might include aberrant lower pole segment vessels that com- 


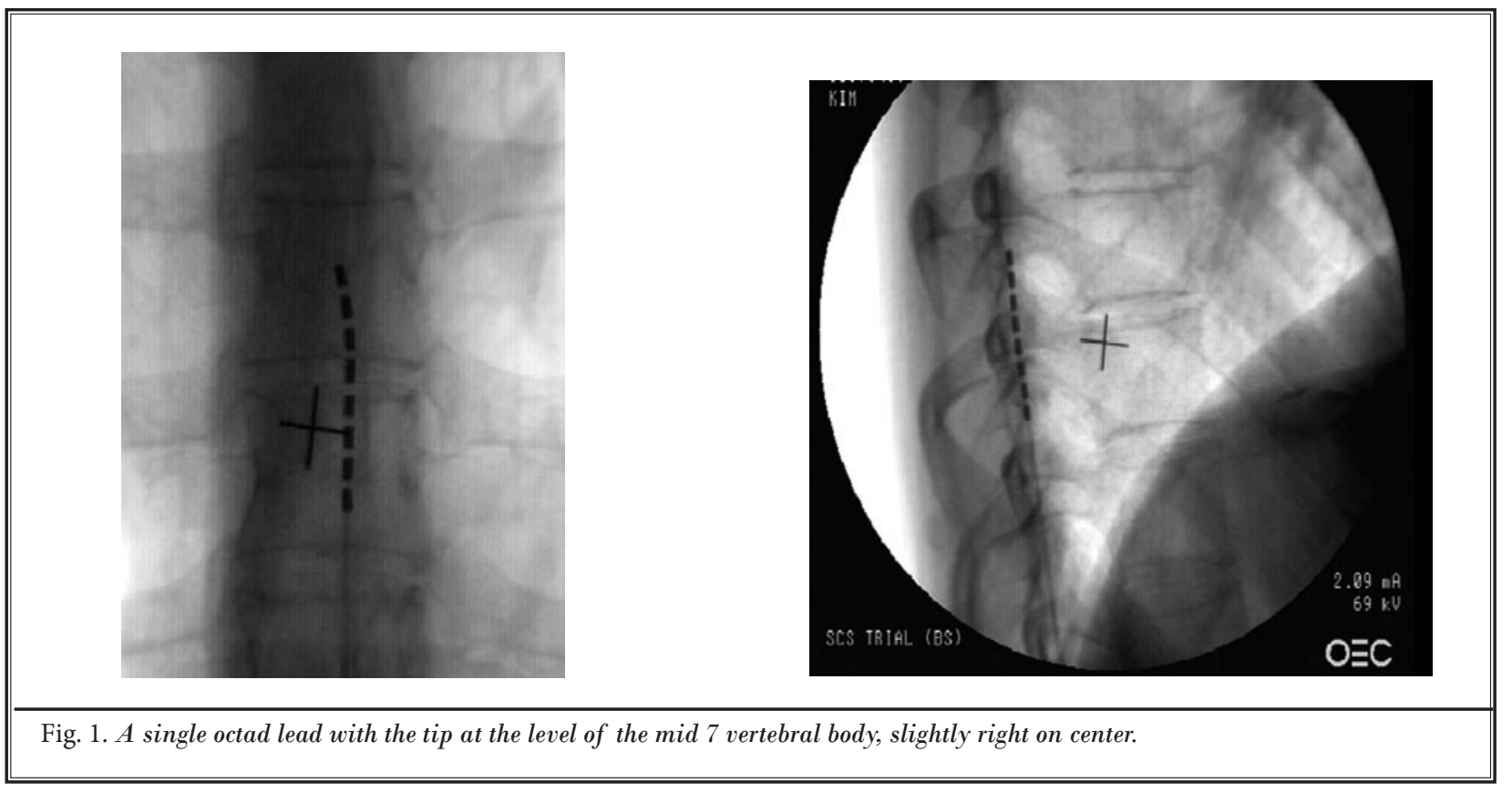

press the ureter, high insertion of the ureter, or renal malrotation. All etiologies usually result in renal pelvic distension and hydronephrosis, the grade of which will depend on the degree of severity of the stenosis at the ureteropelvic junction.

Most common clinical manifestations of patients with UPJO include flank pain, upper urinary tract infection (UTI) and renal calculi secondary to inadequate urinary drainage. Over time, impairment or deterioration in renal function can occur in the affected renal unit. Definitive treatment for symptomatic patients with UPJO includes reconstructive surgery to eliminate the obstruction or nephrectomy. However, other alternatives are available for chronic pain management in these patients, which range from systemic analgesics to physical interventions such as TENS and autonomic plexus blockade.

The kidneys and ureters are well supplied by sympathetic, parasympathetic, and sensory afferent fibers, and renal sensory innervation is clearly associated with the perception of pain in the affected individuals (30). The sympathetic supply comes from the aorticorenal and celiac ganglia as well as from the cephalad portion of the lumbar sympathetic trunk. These fibers originate in segments T8 - L2, and the post-ganglionic sympathetic nerves from the aorticorenal and celiac plexi then join the renal plexus. Sensory innervation of the kidneys comes mainly from the 10th through 12th thoracic spi- nal nerves, but could rise as high as T6 and as low as L2, especially on the right side (31). In this study, the target area was the T7-T8 level in the midline according to the dermatomal distribution of pain and its corresponding spinal levels.

Since both sympathetic and parasympathetic nerves relay via the celiac plexus, celiac plexus blocks have been increasingly used for management of moderate to severe chronic malignant (21) and non-malignant (22-24) pain from various abdominal viscera. In this case, a celiac plexus block was initially offered to the patient but no significant relief was obtained. Since most of her pain was localized to the lower abdomen and pelvis, the ureter and bladder were thought to be another possible source of her pain and accordingly, we suggested performing a superior hypogastric block as an alternative. This resulted in moderate, but limited, reduction in her pain. However, substantial long-term pain relief was still lacking.

SCS is a minimally invasive and reversible treatment option that may be employed as a later option therapy in the treatment of chronic visceral abdominal/pelvic pain. There are previous reports documenting the therapeutic effect of SCS on various types of long-standing visceral abdominal and pelvic pain (11-16). So far, previous reported indications included mesenteric ischemia (20), irritable bowel syndrome (12), chronic pancreatitis (14), diffuse abdominal adhesions (15), painful attacks 
of familial Mediterranean fever (16) and chronic visceral pelvic pain after long-standing endometriosis (4). To the best of our knowledge, there has been no previous report on the use of SCS in the treatment of pain secondary to chronic renal disease. However, Bajwa et al (19) suggested it as an acceptable alternative for pain management in polycystic kidney disease. Previously published small case series studies of SCS for abdominal and pelvic visceral pain have also shown encouraging improvements in pain scores [11-15], improved functional capacity [11], and reduced opioid use $(11,13,14)$.

Various neurophysiological and neurochemical mechanisms underlying the beneficial effects of SCS have been proposed (32-33). In general, electric stimulation to the dorsal column, which contains large diameter afferent fibers, inhibits transmission of nociceptive information at the spinal segmental level. This finding implicates elements of the gate control theory (34), although activation of supraspinal circuits might also be involved (35). However, the exact mechanism of suppression of visceral pain by SCS still remains unclear. The mechanisms evoked by SCS have primarily addressed relief of somatic pain, particularly neuropathic pain. Few studies have examined the effects of SCS on visceroreceptive transmission in the spinal cord. Recently, these studies have shown that SCS suppresses or attenuates the nociceptive visceromotor reflex produced by colorectal distension in rats confirming that it can modulate visceral responses at least in an animal model $(10,17,18)$.

Another proposed mechanism of pain suppression includes an increase in the local visceral blood flow which might help reduce pain related to ischemia. Epidural stimulation of the spinal cord might improve ischemic conditions by suppressing sympathetic activity to the kidney at weak or moderate intensity and might recruit antidromic vasodilation mediated by (full name of CGRP needed first) CGRP release when the intensity of SCS is increased (36-39). These theories might be applicable in this patient since UPJO, whether as a result of intrinsic or extrinsic factors, usually results in pelvic distension and inflammation which in turn could impede the blood supply to the kidney.

\section{Conclusion}

Patients with persistent pain secondary to chronic kidney disease might pose a management challenge to many physicians. Conservative modalities such as medications and physical measures should be utilized initially to maximize functionality and minimize risk to the patient. Interventional pain therapies such as autonomic plexus blockade can also be considered to palliate persistent pain symptoms. In those patients who fail to respond to conservative and interventional therapies, spinal cord stimulation might provide a viable option in the management of pain related to chronic renal disease. However, it should be emphasized that SCS is just to ameliorate the pain. Specialists should evaluate UPJO and make sure that there are no specific interventions to alleviate UPJO which could eventually help relieve the pain.

\section{References}

1. Kumar K, Taylor RS, Jacques L, Eldabe $\mathrm{S}$, Meglio M, Molet J, Thomson S, O'Callaghan J, Eisenberg E, Milbouw G, Buchser E, Fortini G, Richardson J, North RB. Spinal cord stimulation versus conventional medical management for neuropathic pain: A multicentre randomized controlled trial in patients with failed back surgery syndrome. Pain 2007; 132:179-188.

2. Grabow TS, Tella PK, Raja SN. Spinal cord stimulation for complex regional pain syndrome: An evidence based medicine review of the literature. Clin J Pain 2003; 19:371-383.

3. Manchikanti L, Falco FJ, Boswell MV, Hirsch JA. Facts, fallacies, and politics of comparative effectiveness research: Part 2 - implications for interventional pain management. Pain Physician 2010; 13:E55-E79.
4. Manchikanti L, Datta S, Gupta S, Munglani R, Bryce DA, Ward SP, Benyamin RM, Sharma ML, Helm II S, Fellows B, Hirsch JA. A critical review of the American Pain Society clinical practice guidelines for interventional techniques: Part 2. Therapeutic interventions. Pain Physician 2010; 13:E215-E264.

5. Lowry AM, Simopoulos TT. Spinal cord stimulation for the treatment of chronic knee pain following total knee replacement. Pain Physician 2010; 13:251-256.

6. McJunkin TL. Wuollet AL, Lynch PJ. Sacral nerve stimulation as a treatment modality for intractable neuropathic testicular pain. Pain Physician 2009; 12;991-995.

7. Manchikanti L, Boswell MV, Datta S, Fellows B, Abdi S, Singh V, Benyamin RM, Falco FJ, Helm S, Hayek SM, Smith HS;
ASIPP. Comprehensive review of therapeutic interventions in managing chronic spinal pain. Pain Physician 2009; 12: E123-E198.

8. Manchikanti L, Boswell MV, Singh V, Benyamin RM, Fellows B, Abdi S, Buenaventura RM, Conn A, Datta S, Derby R, Falco FJ, Erhart S, Diwan S, Hayek SM, Helm S, Parr AT, Schultz DM, Smith HS, Wolfer LR, Hirsch JA; ASIPP-IPM. Comprehensive evidence-based guidelines for interventional techniques in the management of chronic spinal pain. Pain Physician 2009; 12:699-802.

9. Frey ME, Manchikanti L, Benyamin RM, Schultz DM, Smith HS, Cohen SP. Spinal cord stimulation for patients with failed back surgery syndrome: A systematic review. Pain Physician 2009; 12:379397. 
10. Greenwood-Van Meerveld B, Johnson $A C$, Foreman RD, Linderoth B. Attenuation by spinal cord stimulation of a nociceptive reflex generated by colorectal distention in a rat model. Auton Neurosci 2003; 104:17-24.

11. Kapural L, Janicky T, Narouze S, Mekhail N. Spinal cord stimulation is an effective treatment for the chronic intractable pelvic visceral pain. Pain Med 2006; 7:440-443.

12. Krames E, Mousad DG. Spinal cord stimulation reverses pain and diarrheal episodes of irritable bowel syndrome: A case report. Neuromodulation 2005; 8:82-88.

13. Khan YN, Raza SS, Khan EA. Application of spinal cord stimulation for the treatment of abdominal visceral pain syndromes: Case reports. Neuromodulation 2005; 8:14-27.

14. Kapural L, Rakic M. Spinal cord stimulation for chronic visceral pain secondary to chronic non-alcoholic pancreatitis: A case report. J Clin Gastroenterol 2008; 42:750-751.

15. Tiede JM, Ghazi SM, Lamer TJ, Obray JB. The use of spinal cord stimulation in refractory abdominal visceral pain: Case reports and literature review. Pain Prac 2006; 6:197-202.

16. Kapur S, Mutagi H, Raphael J. Spinal cord stimulation for relief of abdom inal pain in two patients with familial Mediterranean fever. $\mathrm{Br} /$ Anaesth 2006;97:866-868.

17. Qin C, Lehew RT, Khan KA, Wienecke GM, Foreman RD. Spinal cord stimulation modulates intraspinal colorectal visceroreceptive transmission in rats. Neurosci Res 2007; 58:58-66.

18. Qin C, Farber JP, Linderoth B, Shahid A, Foreman RD. Neuromodulation of thoracic intraspinal visceroreceptive transmission by electrical stimulation of spinal dorsal column and somatic afferents in rats. J Pain 2008; 9:71-78.

19. Bajwa Z, Gupta S, Warfield C, Steinman T. Pain management in polycystic kid- ney disease. Kidney Int 2001; 60:16311644.

20. Ceballos A, Cabezudo L, Bovaira M, Fenollosa P, Moro B. Spinal cord stimulation: A possible therapeutic alternative for chronic mesenteric ischemia. Pain 2000; 87:99-101.

21. Staats PS, Kost-Byerly S. Celiac plexus blockade in a 7-year- old child with neuroblastoma. J Pain Symptom Manage 1995; 10:321- 324 .

22. Fugere F, Lewis G. Celiac plexus block for chronic pain syndromes. Can J Anaesth 1993; 40:954-963.

23. Collazos J, Mayo J, Martinez E. Celiac plexus block as treatment for refractory pain related to sclerosing cholangitis in AIDS patients. J Clin Gastroenterol 1996; 23:47-49.

24. Tanelian D, Cousins MJ. Celiac plexus block following high dose opiates for chronic non-cancer pain in a fouryear-old child. J Pain Symptom Manage 1989; 4:82-85.

25. Smith CC, Lin JL, Shokat M, Dosanjh SS, Casthely D. A Report of paraparesis following spinal cord stimulator trial, implantation and revision. Pain Physician 2010; 13:357-363.

26. Yearwood TL, Hershey B, Bradley K, Lee D. Pulse width programming in spinal cord stimulation: A clinical study. Pain Physician 2010; 13:321-335.

27. Wininger KL, Deshpande KK, Deshpande KK. Radiation exposure in percutaneous spinal cord stimulation mapping: A preliminary report. Pain Physician 2010; 13:7-18.

28. Falco FJE, Berger J, Vrable A, Onyewu O, Zhu J. Cross Talk: A new method for peripheral nerve stimulation. An observational report with cadaveric verification. Pain Physician 2009; 12:965-983.

29. Tripp BM, Homsy YL. Neonatal hydronephosis-the controversy and the management. Pediatr Nephrol 1995; 9:503-505.

30. Ansell J, Gee W, Bonica J. Diseases of the Kidney and Ureter. In: Bonica J (ed). The Management of Pain, Volume 2 [2nd ed]. Lea \& Febiger, Philadelphia, PA, 1990, pp 1232-1249.

31. Barajas L, Liu L, Powers K. Anatomy of the renal innervation: Intrarenal aspects and ganglia of origin. Can J Physiol Pharmacol 1992; 70:735-749.

32. Linderoth B, Foreman RD. Physiology of spinal cord stimulation: Review and update. Neuromodulation. 1999; 2:150-164.

33. Linderoth B, Foreman RD. Mechanisms of spinal cord stimulation in painful syndromes: Role of animal models. Pain Med 2006; 7:S14-S26.

34. Melzack R, Wall PD. Pain mechanisms: A new theory. Science 1965; 150:971979.

35. El-Khoury C, Hawwa N, Baliki M, Atweh SF, Jabbur SJ, Saade NE. Attenuation of neuropathic pain by segmental and supraspinal activation of the dorsal column system in awake rats. Neuroscience 2002; 112:541-553.

36. Linderoth B, Fedorcsak I, Meyerson BA. Peripheral vasodilation after spinal cord stimulation: Animal studies of putative effector mechanisms. Neurosurgery 1991; 28:187-195.

37. Linderoth B, Fedorcsak I, Meyerson BA. Is vasodilation following dorsal column stimulation mediated by antidromic activation of small diameter afferents? Acta Neurchir Suppl (Wein) 1989; 46:99-101.

38. Linderoth B, Gunasekera L, Meyerson B. Effects of sympathectomy on skin and muscle microcirculation during dorsal column stimulation: Animal studies. Neurosurgery 1991; 29: 874879.

39. Croom JE, Foreman RD, Chandler MJ, Barron KW. Cutaneous vasodilation during dorsal column stimulation is mediated by dorsal roots and CGRP. AM J Physiol 1997; 272:H950-H957. 
